\title{
Regulation and function of TPL-2, an lкB kinase-regulated MAP kinase kinase kinase
}

\author{
Thorsten Gantke ${ }^{1}$, Srividya Sriskantharajah ${ }^{1}$, Steven C Ley ${ }^{1}$
}

${ }^{I}$ Division of Immune Cell Biology, National Institute for Medical Research, Mill Hill, London, NW7 1AA, UK

Cell Research (2011) 21:704. doi:10.1038/cr.2011.61; published online 5 April 2011

Correction to: (2011) 21:131-145. doi:10.1038/cr.2010.173; published online 7 December 2010

The authors apologize for incorrect citation of the work of Richard Lamb and colleagues on the regulation of TPL-2 by nutrient availability (page 137, top right column, reference 54). The correct reference for this research is:

Mieulet V, Yan L, Choisy C, et al. TPL-2-mediated activation of MAPK downstream of TLR4 signaling is coupled to arginine availability. Sci Signal 2010; 3:ra61. 